\title{
PESCA ARTESANAL AÇORIANA \\ Oportunidades de investigação sociológica e seus contributos para a gestão sustentável
}

\author{
AZOREAN ARTISANAL FISHERIES \\ A field of opportunities for sociological research to empower \\ sustainable management
}

\author{
Ana Fraga \\ Universidade Nova de Lisboa, Faculdade de Ciências Sociais e Humanas, CICS.NOVA - Centro Interdisciplinar \\ de Ciências Sociais \& Autoridade Marítima Nacional, Av. de Berna, 26-C, 1069-061 LISBOA, Portugal. \\ Email: ana.rita.fraga@marinha.pt \\ Lucinda Jordão \\ Técnica Superior de Serviço Social. Email: lucindamajordao@hotmail.com
}

\begin{abstract}
Resumo: O presente ensaio tem como objetivo a partilha de considerações críticas iniciais acerca da importância da investigação sociológica sobre as problemáticas associadas à sustentabilidade da pesca de pequena escala e ao desenvolvimento local sustentável. Assumindo a Pesca Artesanal Açoriana enquanto esfera de investigação das ciências sociais, mais do que apresentar conclusões fechadas, nesta análise crítica procura-se avançar com contributos que estimulem a reflexão em torno da responsabilidade da pesquisa sociológica face aos desafios que se impõem nesta área temática, assim como refletir sobre a importância dos contributos científicos das ciências sociais no âmbito de uma estratégia de intervenção local e gestão sustentada. As reflexões ora partilhadas emergem de resultados obtidos em pesquisa de campo, numa abordagem ao terreno durante a qual foram recolhidos registos de observação participante a par com a realização de um pequeno questionário exploratório e sessões de focus group com atores locais.
\end{abstract}

Palavras-chave: pesca artesanal, sistemas socioecológicos, representações sociais, desvio.

\begin{abstract}
The following essay presents some critical considerations about the importance of sociological research focused on issues of small-scale fisheries sustainability and local sustainable development. Assuming the Azorean Artisanal Fisheries as an object of research in Social Sciences, this critical analysis gives some inputs to promote a wider reflexion about the responsibility of sociological research when addressing the challenges that small-scale fisheries are facing nowadays. We further aim to give some inputs to the discussion about the need and role of Social Sciences contributes when working in intervention strategies and sustainable management. These reflections emerge from field research, in which participant observation notes were collected, an exploratory survey was applied and focus group sessions with local actors took place.
\end{abstract}

Keywords: artisanal fisheries, social-ecological systems, social representations, deviance.

\section{Considerações prévias}

O presente ensaio apresenta-se como um exercício de reflexão crítica sobre a necessidade de haver uma maior preocupação pelas ciências sociais, especificamente 
pela sociologia, em torno das problemáticas sociais que emergem da atual conjetura do setor das pescas e gestão dos recursos (pesqueiros mas também habitats). Não se trata de um artigo de apresentação e discussão de resultados finais de um estudo, mas antes apresentação da importância e pertinência do "acompanhamento" dos processos de gestão das pescas e dos recursos marinhos e habitats pelas ciências sociais. Com o intuito de contextualizar a reflexão proposta, avança-se uma breve apresentação da problemática sociológica que a investigação em curso aborda - pesca ilegal/práticas piscatórias desviantes - não sendo objetivo do presente ensaio discutir esta problemática em si.

Não sendo a esfera da pesca artesanal e a realidade açoriana comummente conhecida nem objeto frequentemente presente no discurso da investigação sociológica em Portugal, a apresentação de conteúdos é feita por modo a propor o seguinte itinerário: 1) Inicia-se o presente ensaio com uma breve apresentação do contexto do qual emerge a reflexão proposta e introdução da conjetura na qual se enquadra o problema da pesca ilegal por modo a balizar as práticas ilegais enquanto problemática sociológica, cuja importância reside no seu papel central com vista à compreensão do modus operandi e praxis tradicional da atividade piscatória açoriana e dos contornos do conflito entre práticas/mundivisões dos atores locais e políticas públicas; 2) Seguidamente avança-se com a delimitação de conceitos-chavee referencial epistemológico no qual se ancora a reflexão proposta; 3) Após esta contextualização de contexto e referências, procede-se a uma entrada em que se aborda "o lugar das pescas" no âmbito das políticas públicas regionais: partindo de uma breve contextualização circunstancial este ponto assume uma importância central no presente ensaio pela breve análise do estado da arte da investigação pelas ciências sociais que avança, com o objetivo de reforçar a pertinência da abordagem pelas ciências sociais ao setor das pescas - partindo da visão de atores chaves do processo de gestão do setor no tecido regional, destaca-se a questão da necessidade da investigação multidisciplinar concertada e consequente conhecimento efetivo dos contornos da atividade piscatória artesanal (no seio da sua própria realidade circunstancial) para que seja possível a promoção de uma gestão sustentável do setor e dos ecossistemas em que a atividade se inscreve; 4) Segue-se um ponto que aborda as oportunidades de trabalho na esfera de investigação sociológica, procurando-se avançar com contributos para uma abordagem ecosistémica a partir do estudo Representações sociais dos atores da pesca artesanal açoriana sobre as políticas públicas para a gestão sustentável dos recursos marinhos nas Ilhas Reserva da Biosfera: por modo a contextualizar as considerações avançadas a propósito do lugar do contributo dos atores locais e oportunidades no terreno no âmbito da investigação científica ecosistémica, apresenta-se de forma sucinta a metodologia de trabalho 
que tem vindo a ser aplicada ao longo da pesquisa que motivou a presente reflexão, a qual se partilha com o objetivo de contribuir para o processo de construção de uma metodologia de abordagem à pesca pelas ciências sociais e em processos de trabalho em cooperação interdisciplinar. 5) Por fim tecem-se considerações finais cujo foco se coloca na necessidade de investimento na produção de conhecimento sobre os atores da pesca e sobre as dinâmicas locais da atividade piscatória. Sendo uma necessidade identificada após uma análise crítica do estado da arte, esta postula-se como necessidade identificada pelos próprios atores locais e constitui em si um espaço de oportunidades de trabalho no âmbito da investigação sociológica, enquanto contributo fundamental para os processos e estratégias concertadas de desenvolvimento local sustentável das comunidades costeiras.

\section{Introdução}

O arquipélago dos Açores e a região oceânica que o rodeia são um importante repositório de biodiversidade com relevância a nível planetário, que necessita de uma adequada proteção que compense as naturais vulnerabilidades resultantes da pequena extensão dos ecossistemas insulares, do isolamento entre ilhas e em relação às regiões continentais, da fragmentação e perda de habitats e da fragilidade das espécies autóctones face a organismos invasores. (...) Em matéria de proteção da biodiversidade, o primeiro esforço foi feito através do Decreto Legislativo Regional n. ${ }^{\circ}$ 2/83/A, de 2 de março, que estabeleceu normas relativas à preservação do equilíbrio ecológico designadamente através da proibição da caça dos golfinhos (toninhas) que frequentam os mares dos Açores. (...) Aquele diploma, pioneiro na proteção dos cetáceos nas águas sob jurisdição portuguesa, iniciou um conjunto de intervenções legislativas no âmbito da conservação da natureza (...).

Assembleia Legislativa da Região Autónoma dos Açores ${ }^{1}$

Localizada no meio do hemisfério norte do Oceano Atlântico, a Região Autónoma dos Açores é composta por nove ilhas vulcânicas que pertencem à região biogeográfica da Macaronésia, as quais se estendem ao longo de uma área de aproximadamente 600 quilômetros de largura. Apresentando cada uma as suas próprias caraterísticas, importa destacar que existem grandes diferenças entre as nove ilhas em termos de totais de habitantes, densidade demográfica e tecido sociodemográfico, assim como consideráveis diferenças no que respeita às peculiaridades locais das dinâmicas socioeconómicas.

Quatro das ilhas de menor dimensão (Graciosa, S. Jorge, Flores e Corvo) estão classificadas como Reservas da Biosfera pela Organização das Nações Unidas para 
a Educação, Ciência e Cultura (UNESCO), no âmbito do Programa Homem e Biosfera (MAB), classificação que compreende a promoção de soluções que conciliam a conservação da biodiversidade com seu uso sustentável, com o objetivo de promover abordagens socioeconómicas que, aliando conhecimentos científicos e estratégias de governança, visem reduzir a perda de biodiversidade e melhorar os meios de subsistência das populações. São, assim, espaços de excelência e de suporte de Ciência para Sustentabilidade, onde as abordagens interdisciplinares devem focar a compreensão e gestão das interações entre sistemas sociais e ecológicos, incluindo prevenção de conflitos decorrentes da implementação de estratégias que apostam a gestão da conservação da biodiversidade, a fim de favorecer as condições sociais, económicas e culturais essenciais à viabilidade do desenvolvimento sustentável. ${ }^{2}$

É este o contexto em que se enquadra a presente proposta de reflexão crítica. Atualmente, a atividade de pesca artesanal nas ilhas açorianas da "Biosfera" enfrenta um conjunto de problemas e desafios face ao emergir de um novo quadro legal, o qual visa o uso e exploração sustentável dos recursos marinhos e a conservação dos ecossistemas costeiros. O novo enquadramento jurídico trouxe a consciência da necessidade de promover uma pesca responsável para garantir o equilíbrio ambiental e o desenvolvimento sustentável desta atividade por parte dos vários atores envolvidos nesta atividade, assim como parece estar na origem de determinados focos de conflito sinalizados através de práticas piscatórias contraordenacionais, ${ }^{3}$ as quais poderão, por sua vez, ser sinalizadas enquanto obstáculo ao sucesso das políticas públicas regionais e da estratégia definida para estas Reservas da Biosfera. Com efeito, sendo a frota açoriana maioritariamente artesanal, esta opera com embarcações de pesca local e costeira, essencialmente até às 12 milhas náuticas, em pesqueiros tradicionais onde nos últimos anos a atividade tem vindo a ser condicionada. Com efeito, seja pela implementação de novas zonas de reserva natural e zonas marinhas protegidas, seja pela introdução de medidas que visam a proteção de determinadas espécies, nos últimos anos assistiu-se a uma redução das áreas disponíveis para a faina, ${ }^{4}$ situação que afeta principalmente a frota de pesca local (embarcações com um comprimento fora-a-fora até 9m que operam maioritariamente até às 3 milhas náuticas), a qual representa cerca de $71 \%$ da frota total. Ora, este é um problema sinalizado pelas comunidades piscatórias nas ilhas da Biosfera, onde, a par com o novo quadro de medidas regionais para preservação dos recursos marinhos, foram criadas áreas protegidas que, em alguns casos, coincidem com as zonas de pesca sinalizadas pelas populações locais como sendo tradicionalmente "bons pesqueiros", nomeadamente no inverno, quando o tempo obriga a operar mais resguardado junto a terra. No terreno, observa-se a resistência ao cumprimento destas disposições legais, que se consubstancia num elevado 
número de práticas contraordenacionais (umas formalmente sinalizadas e tornadas públicas através do levantamento de autos de notícia pelas entidades fiscalizadoras, outras publicamente reconhecidas como comuns, mas não sinalizadas oficialmente) (Fraga, 2016).

Destaca-se, aqui, que a atividade da pesca artesanal é uma atividade importante no arquipélago dos Açores, com grande impacto ao nível da coesão socioeconómica dos tecidos locais/ilha, especialmente nas ilhas mais pequenas. Esta importância é assumida de forma clara pelo Governo Regional dos Açores, o qual, a propósito do papel estratégico da pesca comercial na Região, assume que "a pesca, sendo um dos usos mais antigos do espaço marítimo, continua a ser um subsetor de grande importância, com um peso elevado na Região Autónoma dos Açores, não apenas em termos de valor acrescentado, mas sobretudo como fonte de emprego" (Direção Regional dos Assuntos do Mar, S.d, p. 14).

Face aos novos desafios traçados com vista à preservação ambiental, o sucesso do desenvolvimento sustentável da faixa costeira das ilhas açorianas depende de modo significativo do respeito pelas regras de preservação dos recursos e habitats estabelecidas recentemente (nomeadamente no que respeita o cumprimento das regras aplicáveis às áreas marinhas protegidas e zonas marinhas de reserva) (Fraga, 2017). Importa, assim, compreender em que sentido se figura pertinente a promoção de uma estratégia concertada de produção de conhecimento sobre o setor na região, o qual permita uma leitura efetiva da realidade circunstancial da atividade em cada ilha e que promova um mapeamento das representações sociais dos atores da pesca artesanal sobre as políticas públicas para o setor. Este investimento na produção de conhecimento sobre os atores da pesca e sobre as dinâmicas locais da atividade piscatória figura-se, neste sentido, como fundamental com vista à compreensão do modus operandi e praxis tradicional da atividade piscatória açoriana e dos contornos do conflito, sinalizados no terreno, entre práticas/mundivisões dos atores locais e políticas públicas.

\section{Delimitação de conceitos-chave e referencial epistemológico}

Ancorada num exercício de análise e reflexão sociológica mais abrangente no contexto do trabalho de pesquisa desenvolvido, sob o tema Representações sociais dos atores da pesca artesanal açoriana sobre as políticas públicas para a gestão sustentável dos recursos marinhos das Ithas Reserva da Biosfera (Graciosa, S. Jorge, Flores e Corvo), ${ }^{5}$ a presente abordagem tem por base as reflexões teóricas contemporâneas sobre a importância da participação concertada dos atores locais em estratégias de utilização e exploração sustentável dos recursos pesqueiros, em salvaguarda da conservação 
dos recursos marinhos e preservação dos habitats. ${ }^{6}$ Apresenta-se este exercício com o objetivo de partilha de algumas considerações relativamente às dificuldades, necessidades e oportunidades que se colocam à investigação sociológica que aborda a área temática da pesca e ecossistemas em que esta atividade se inscreve. Assumindo a Pesca Artesanal Açoriana enquanto esfera de investigação sociológica, mais do que apresentar conclusões fechadas, a abordagem proposta procura avançar com contributos que estimulem a reflexão em torno da responsabilidade dos sociólogos face aos desafios que se impõem nesta área temática, assim como importância dos contributos científicos das ciências sociais no âmbito de uma estratégia de intervenção local sustentada. ${ }^{7}$

O termo "pesca artesanal" assume, neste sentido, um papel central no presente ensaio. Termo usual no registo do senso comum, trata-se, no entanto, de um termo polémico, não só pelas diferenças de uso que se registam em diversos documentos oficiais (legais ou políticos, nos quais os termos "pesca artesanal”, "pesca local" e "pesca de pequena escala" são frequentemente assumidos como sendo sinónimos), mas também pela dificuldade de encontrar uma definição consensual no seio da comunidade científica.

No presente estudo circunscrevemos a definição do termo pesca artesanal por referência aos contributos de Souto (2003): a) Subsistema de pesca que se desenvolve num ambiente económico, legal e administrativo particular; b) Atividade económica caracterizada pela forma tradicional como se organiza: i) Embarcações de pequena dimensão que exercem a sua atividade em pesqueiros relativamente próximos da costa (pesca local ou costeira), ii) Pescador - trabalhador/proprietário dos meios de produção (artes e embarcações), sistemas remuneratórios que se baseiam no rendimento da atividade (remuneração "à parte" com suplementos de peixe), grande diversidade de artes de pesca, do tipo passivo; c) 4 Tipos de pesca artesanal: i) De base estritamente familiar; ii) De base familiar; iii) Em transição; iv) Formas atípicas.

Assume-se a terminologia de pesca artesanal açoriana para designar a atividade piscatória que se desenvolve na região, a qual tem caraterísticas distintas da pesca realizada nas demais regiões do país ${ }^{8}$ e é regulamentada por um quadro legal próprio. ${ }^{9}$

Considerando a abordagem proposta por Ostrom (2009) e Bruckmeier (2016), a pesca artesanal açoriana, enquanto objeto de estudo das ciências sociais, é caracterizada como um sistema socioecológico. Este conceito remete para a integração dos processos e componentes socioeconómicos e biofísicos de um objeto, assim considerado como um todo, que funciona de forma metabólica. A imagem de metabolismo socioecológico encerra a necessária compreensão de que o uso que 
as pessoas fazem da natureza está embutido no sistema socioeconómico (seus valores, relações sociais e políticas, direito de uso, leis, governança, mercado e relações económicas, etc.). Trata-se de um sistema vivo complexo, com componentes sociais e ecológicas, barreiras espaciais e funcionais, com capacidade adaptativa (system-maintaining) e transformativa (system-modifiyng). Bruckmeier (2016, Table 4.2) caracteriza a pesca de pequena escala como sendo um sistema socioecológico de produção (económica) primária, no qual as relações ecológicas são dominantes (sistema altamente dependente do contexto ecológico em que se inscreve).

Em relação ao uso da terminologia políticas públicas, este conceito é aqui assumido considerando a sua dupla dimensão, que na língua inglesa se distingue em politic e policy. Considera-se quer a dimensão da visão e posicionamento subjacentes à gestão da res publica (policy), a qual, segundo Secchi (2010) refere as orientações (princípios e valores) para a decisão e ação das políticas públicas, quer a dimensão formal e concretas dessas mesmas políticas.

No que respeita os referenciais teóricos sobre os quais esta reflexão se alicerça, destaca-se o legado de Elinor Ostrom (Ostrom, 1990; 1997; 2008; Ostrom, Gardner \& Walker, 1994; Ostrom \& Hess, 2006; Ostrom, Wynne \& Schroeder, 1993) sobre a participação concertada dos atores locais em estratégias de exploração sustentável dos recursos pesqueiros (gestão dos comuns), a par com as considerações de Karl Bruckmeier (2016) acerca dos contributos da abordagem ecossistémica em torno da problemática da sustentabilidade, destacando a importância dada por este autor à necessária dialética entre a pesquisa de terreno e a pesquisa teorética.

Tomam-se de igual modo os contributos de Faugeron et al. (1976) e Merton (1964) no que respeita a problemática sociológica das motivações para o desvio e a proposta de Jodelet (1989) para a abordagem sociológica às representações sociais, tendo como linha orientadora a abordagem de Dubet (1994) à ação humana.

O conceito de "desvio" é, com efeito, nuclear nesta reflexão crítica. Colocando-se o desafio da compreensão das razões de ser (valores e motivações) que levam os atores a posicionarem-se criticamente contra as políticas públicas de proteção ambiental (as quais se consubstanciam no quadro legal vigente) e a praticar ações contraordenacionais (que consubstanciam infrações a normas legais), importa esclarecer como se entende aqui o conceito de "desvio". Considerando "a diversidade e abrangência das teorias sobre o desvio" (Lima, 2001, p. 186), a presente abordagem tem por referência as teorias interacionistas de enfoque ecológico da Escola de Chicago, cujas reflexões sobre o "fenômeno do desvio são baseadas em princípios ligados às definições de normas de vida em sociedade" (Lima, 2001, p. 187). Toma-se, assim, por referência de partida o conceito de desvio conforme definido por Faugeron et al. (1976): um fenómeno de desvio identifica-se enquanto 
sinal da diferença. Concordando com este autor, assume-se que o desviante é-o quando percebido e representado enquanto diferença face o ordinário reconhecido como tal dentro de um grupo social (Faugeron et al., 1976), isto é, o que se configura como norma.

A partir desta definição de desvio enquanto diferença, considera-se igualmente a perspetiva de Berger (1966), segundo o qual a ordem social existe enquanto resultante da atividade humana em relação permanente de equilíbrio entre fenómenos sociais. Ora, quando dentro da mesma esfera de ação diversos atores interagem, estão em jogo conflitos e tensões entre fenómenos sociais. Quando esta relação dialética de equilíbrio fica comprometida a ordem social é posta em causa, espaço em que situamos a ação desviante. A este propósito, consideram-se os contributos de Merton (1964), o qual chama a atenção para a necessidade de compreender o desvio enquanto manifestação de um desequilíbrio da situação social, o qual condiciona a estabilidade da própria estrutura social.

Por fim, importa ainda esclarecer o conceito "representações sociais", tomado na aceção de Denise Jodelet: "forma de conhecimento, socialmente elaborada e partilhada, tendo uma visão prática e concorrendo para a construção de uma realidade comum a um conjunto social" (Jodelet, 1989, p. 22). Este conceito será mobilizado enquanto referencial conceptual dos atores: o conjunto de representações sociais de cada indivíduo é assumido enquanto "grelha" que medeia a interpretação deste face ao circundante em que emerge e a partir da qual cada ator medeia a sua interação com a realidade social em que se inscreve.

\section{O lugar das pescas no âmbito das políticas públicas regionais: breve contextualização circunstancial e estado da arte da investigação pelas ciências sociais}

Em 2007, João Mira Gomes, Secretário de Estado da Defesa Nacional e dos Assuntos do Mar, no prefácio do documento oficial que tornava pública a nova Estratégia Nacional para o Mar 2006-2016,10 afirmava que "O desenvolvimento das atividades que se exercem no mar e nas zonas costeiras é, simultaneamente, uma oportunidade e um desafio para Portugal" (Ministério da Defesa Nacional, 2007, p. 5). Ainda na mesma comunicação é reforçada a necessidade de empenho na promoção de formas inovadoras de aproveitamento sustentável dos recursos do oceano, procurando resolver conflitos de uso e potenciando sinergias e garantindo a proteção e salvaguarda do património subaquático natural e cultural.

Com efeito, a emergente aposta no Cluster do Mar e o reconhecimento da importância estratégica que o setor marítimo pode ter na economia portuguesa são 
questões que se encontram na ordem do dia, como seja no plano das estratégias governamentais nos Assuntos do Mar (que seguem a atual agenda internacional dos oceanos, nomeadamente no que respeita à futura Política Marítima da União Europeia).

Acompanhando os desenvolvimentos das novas políticas para o Atlântico Norte e a estruturação de parcerias para o Cluster do Mar no plano nacional, começa a ganhar consistência uma realidade de ação económica em torno dos potenciais económicos das áreas marítimas territoriais portuguesas. Este novo paradigma que se começa a esboçar, agora de um modo mais concreto, e visando uma pro-atividade mais efetiva para a sua concretização estratégica, encara o setor marítimo como um recurso a explorar e a potenciar para uma nova "economia do mar" assente numa visão global e macro que permitirá consolidar o hypercluster do mar como um "desígnio nacional" (AFEM, 2009, p. 362). No entanto, faltam ainda referências de propostas de ação concretas quanto ao "papel" ou "lugar" de alguns dos "tradicionais" atores de exploração económica deste mesmo oceano e cuja importância ao nível das dinâmicas económicas e socioculturais locais é incontornável.

Não obstante, é reconhecido pelo poder político que um dos principais pontos fracos do setor é a "existência de elevado número de pequenas empresas familiares com fraca capacidade de gestão, inovação e introdução de novas tecnologias" (MADRP-DGPA, 2007, p. 17), e também, tendo

em conta os desideratos da Política de Pescas a prazo: Competitividade; Sustentabilidade; $(. .$.$) há que (...) assegurar a coesão económica e social nas zonas fortemente de-$ pendentes da pesca (a redução do esforço de pesca pressupõe um processo de ajustamento estrutural que poderá acarretar algum tipo de crise social nestas zonas, o que requer a tomada de medidas correspondentes). (MADRP-DGPA, 2007, p. 30)

Note-se que a redução do esforço de pesca supracitado refere a prevista redução significativa da frota pesqueira, onde a pesca artesanal/local deverá registar uma maior redução relativa e que a matriz do discurso assenta na premissa "fatalista" de que a pesca artesanal está condenada a perecer.

A este propósito, lançando um breve olhar sobre a questão problemática do "desmembrar contínuo de comunidades piscatórias" (Moniz, Godinho \& Kovács, 2000, p. 3), rapidamente encontramos ecos em discursos vários da sociedade civil e mesmo no discurso que prevalece dentro do setor, remetendo para a crescente preocupação em relação ao futuro das pescas. Contudo, trata-se, segundo o mesmo autor de uma "certeza cientificamente infundada nos moldes em que é taxativamente colocada à luz da ameaça de irremediável colapso dos stocks/ recursos marinhos" (Moniz, Godinho \& Kovács, 2000, p. 4). 
Por outro lado, segundo as recomendações da FAO (2010), urge estabelecer planos efetivos de recuperação da viabilidade do setor, com especial incidência na reabilitação da pesca artesanal, não só pelo facto de se tratar de uma pesca que, se dinamizada de forma responsável e consciente, tem um futuro promissor enquanto prática sustentável (na dimensão ambiental do conceito), mas também por representar uma atividade de incontornável valor social e cultural, valor este, cuja perda se transcreveria em situações problemáticas ao nível das dinâmicas locais de emprego e das manifestações culturais/ etnográficas que estão na génese do património identitário das próprias comunidades piscatórias e comunidades ribeirinhas que lhes são tangentes.

Parafraseando Ricardo Pais de Lacerda (2008), da Federação das Pescas dos Açores, a questão da diminuição dos recursos está na ordem do dia, remetendo especialmente para a questão da sobre-exploração à escala mundial, mas apenas a pesca abusiva não é sustentável. Como salienta,

Este facto de cariz global não encerra em si mesmo nenhuma fatalidade. Ainda vamos a tempo de desenvolver uma atividade da pesca duradoura, geradora de riqueza e emprego, respeitosa das espécies e do meio ambiente. Para tal, torna-se essencial pensar na sua gestão no sentido da concertação entre todos aqueles que obtêm sustento do mar: os que o exploram, estudam e administram, definindo unidades territoriais que façam sentido quer a nível biológico como da atividade humana. (Lacerda, 2008)

É este o sentido que se lê nas linhas orientadoras do Plano Comum de Pescas e da Estratégia de Lisboa, no Plano Estratégico Nacional para a Pesca 2007 - 2013 (MADRP-DGPA, 2007, p. 4), onde se salienta a necessidade de "garantir a sustentabilidade dos recursos, promover a competitividade do setor e assegurar a coesão económica e social das comunidades piscatórias mais dependentes da pesca" (MADRP-DGPA, 2007, p. 4), postulando-se que estas preocupações devem ser assumidas como princípios norteadores "das políticas para o setor da pesca nos próximos anos" (MADRP-DGPA, 2007, p. 4). É ainda neste contexto que é defendido que as políticas públicas para o setor devem assumir o objetivo de assegurar o desenvolvimento das zonas costeiras dependentes da pesca, por modo a garantir o desenvolvimento sustentável das comunidades piscatórias, defendendo-se que “qualquer política pública em favor deste setor deverá contribuir para a estabilidade social e qualidade de vida e bem-estar das populações, com especial relevo para as comunidades piscatórias nas regiões mais dependentes da pesca" (MADRP-DGPA, 2007, p. 37). No quadro nacional das políticas públicas para o setor reconhece-se, deste modo, que esta é uma aposta de particular importância na estratégia de desenvolvimento do setor (Lacerda, 2008) e que "as zonas e localidades 
costeiras tradicionalmente ligadas ao mar [...] constituem um vasto património, tão valioso e insubstituível para as gerações atuais e vindouras, que importa preservar e promover" (MADRP-DGPA, 2007, p. 37).

Efetivamente, Portugal detém uma das maiores Zona Económica Exclusiva (ZEE) da União Europeia, com uma área total de cerca de 1.7 milhões de $\mathrm{km}^{2}$ e conta com mais de 800 quilómetros de costa, ao longo dos quais vivem inúmeras comunidades de pescadores (Souto, 2007), as quais são na sua maioria dependentes da pesca e atividades com ela relacionadas (Beata, 2009). A Subárea dos Açores (ZEEA), de $957.292 \mathrm{~km}^{2}$, representa 55\% da ZEE Portuguesa e 16,3\% da soma das ZEE na União Europeia.

Um debruçar sobre a realidade da Região Autónoma dos Açores permite observar que estes dados assumem especial pertinência se considerarmos a dinâmica socioeconómica da região, uma vez que a pesca assume um papel fulcral, principalmente nas ilhas mais pequenas (nas quais as principais atividades económicas são a pesca e a agropecuária). Em 2015 registou-se um efetivo de 3151 pescadores matriculados $^{11}$ na região (INE, 2011).

Seguindo as mesmas linhas orientadoras da Estratégia Nacional para o Mar 2013-2020, na qual um dos objetivos definidos é precisamente desenvolver atividades de investigação e de inovação tecnológica no âmbito do apoio à fileira da pesca, no Plano Mar - Portugal - Açores (2015-2020), a Secretaria Regional do Mar, Ciência e Tecnologia defende que a investigação científica é fundamental e se encontra na base do desenvolvimento socioeconómico sustentável da região e essencial para a promoção do uso sustentável dos recursos marinhos. Neste documento estruturante das políticas públicas para a região, a pesca comercial é caracterizada como "um subsetor de grande importância, com um peso elevado na Região Autónoma dos Açores, não apenas em termos de valor acrescentado, mas sobretudo como fonte de emprego" (Direção Regional dos Assuntos do Mar, S.d, p. 14).

Com efeito, no que respeita à realidade açoriana, a pesca é uma atividade económica cuja importância no tecido socioeconómico açoriano é igualmente reconhecida pelo Governo Regional, nomeadamente no que respeita o seu impacto socioeconómico e presença sociocultural nas ilhas de coesão (Graciosa, S. Jorge, Santa Maria, Flores e Corvo), onde as atividades da pesca e agropecuária são predominantes, reconhecimento que se reflete nas políticas públicas para gestão e promoção da atividade.

Em termos de caraterísticas de tecido demográfico e socioeconómico este território apresenta caraterísticas muito díspares a vários níveis, verificando-se grandes contrastes em termos de dimensão populacional entre ilhas. Por outro lado, existem também grandes disparidades no que respeita à dinâmica da atividade económica em cada uma das ilhas. 
Não obstante a escassez de estudos que nos permitam falar com alguma propriedade acerca das particularidades do funcionamento e desenvolvimento da atividade, salienta-se que, segundo Natacha Carvalho (2011), investigadora do Departamento de Oceanografia e Pescas da Universidade dos Açores, a pesca artesanal nos Açores é mais rentável e sustentável que a pesca industrial, sendo que em 2015 se registou um efetivo de 2289 embarcações com licença de pesca atribuída (1629: <10m; 514: $10<15 \mathrm{~m}$; 45: 15<24m; 13: > /40m) e foi movimentado em lota um total de 27531000 euros (9100t) (INE, 2016).

Destaca-se ainda que a importância económica da pesca na região se estende também à indústria transformadora da pesca e aquicultura, tendo-se registado em 2014 um volume de negócio de 725540 euros.

Na pesca artesanal açoriana predominam as embarcações e artes artesanais (Rodrigues et al., 2008) e em termos de caraterísticas de frota, esta é constituída maioritariamente por embarcações de pesca local e embarcações de pesca costeira, sendo o número de embarcações de pesca do largo muito reduzido. ${ }^{12}$ No que respeita à frota das ilhas de menor dimensão esta é composta apenas por embarcações de pequena dimensão e a organização da atividade ainda apresenta os moldes tradicionais de negócio familiar, facto que gera elevado grau de dependência na maior parte das famílias de pescadores e armadores.

A distinção de ilhas de coesão, assim, assume um importante papel no contexto de uma reflexão sociológica, uma vez que é precisamente no contexto da estratégia das ilhas de coesão que a pesca artesanal assume uma maior dimensão social em termos de coesão do tecido socioeconómico local e preservação da identidade e património das localidades piscatórias do arquipélago. Tratando-se de um termo de dimensão política, este conceito, recentemente introduzido no dicionário político açoriano no âmbito das políticas públicas regionais pelo Partido Socialista, remete para uma política de discriminação positiva pelo Governo Regional dos Açores, em benefício do desenvolvimento local sustentável e coesão da região, através de um reforço do apoio às populações das ilhas mais pequenas, ${ }^{13}$ nomeadamente através da reorientação dos objetivos do Fundo Regional de Apoio às Atividades Económicas ${ }^{14}$ e a afetação de novas valências e âmbito de intervenção.

Do ponto de vista geográfico, esta é uma região que apresenta uma orla costeira com acentuados recortes, que dão lugar à formação de inúmeras baías e ilhéus a curta distância da linha de costa. Estas caraterísticas são altamente favoráveis para a atividade piscatória, assim como constituem importantes habitats de nidificação de diversas espécies marinhas.

A região apresenta uma extensa área de zonas protegidas, em terra e no mar, contando com a atribuição da classificação da UNESCO de Reserva da Biosfera a 
quatro ilhas: Graciosa, S. Jorge, Flores e Corvo. ${ }^{15}$ A designação "Reserva da Biosfe$r a^{\prime \prime}$, reveste-se de uma dimensão política de discriminação positiva dos territórios classificados, entendendo a sua dimensão e as suas peculiaridades como uma oportunidade de preservação do mundo natural. Sendo o arquipélago dos Açores constituído por nove ilhas, as Políticas Públicas regionais para as ilhas de menor dimensão refletem uma aposta na discriminação positiva face às mesmas. Com o objetivo de promover um desenvolvimento local sustentável destas ilhas, que concilie crescimento económico e a preservação dos baixos níveis de pressão e utilização dos recursos naturais, foi criada a Rede de Áreas Protegidas dos Açores, a qual constitui a estrutura territorial e administrativa básica de conservação da natureza no arquipélago dos Açores e na região oceânica circundante. Esta rede concretiza a classificação em categorias de gestão adotada para as áreas protegidas pela União Internacional para a Conservação da Natureza (IUCN), adaptando-a às particularidades geográficas, ambientais, culturais e político-administrativas do território do arquipélago dos Açores. ${ }^{16}$ Enquadrado nesse processo e no âmbito da operacionalização nos Açores da Rede Natura 2000,17 o Governo Regional dos Açores apostou na inclusão na Rede Mundial de Reservas da Biosfera (World Network of Biosphere Reserves ou WNBR) das ilhas de menor densidade populacional e onde se desenvolveram formas peculiares de convivência entre as comunidades residentes e o ambiente. Estas reservas são administradas no contexto dos respetivos Parques Naturais de Ilhas ${ }^{18}$ e deram origem à criação da marca Biosfera - Açores, utilizada na promoção dos produtos originários daquelas ilhas. Importa referir que a designação Reservas da Biosfera surge enquadrada no Programa da UNESCO Programa MaB (Man and Biosphere), o qual prevê a constituição de uma rede mundial de reservas partindo da identificação de territórios importantes para a conservação da biodiversidade e a promoção do desenvolvimento sustentável, identificando os mecanismos que permitam conciliar a conservação da biodiversidade com o desenvolvimento humano em todas as situações bioclimáticas e geográficas da biosfera.

A este propósito importa salientar que a aposta da região numa estratégia de conservação da biodiversidade e a promoção do desenvolvimento sustentável tem gerado vários focos de conflito entre os atores locais, ${ }^{19}$ não só por oposição e resistência às novas medidas restritivas que foram introduzidas com vista à preservação dos recursos, ${ }^{20}$ mas também por um sentimento generalizado entre os atores locais de incoerência e desajuste destas políticas face às peculiaridades de cada ilha. ${ }^{21}$

Face à estratégia regional de promoção e apoio ao desenvolvimento da pesca artesanal açoriana, para que seja possível a promoção de uma gestão sustentável 
do setor e dos ecossistemas em que a atividade se inscreve, surge a necessidade de uma aposta efetiva por parte das ciências sociais para a promoção da investigação em torno de problemas concretos que emergem deste contexto, para que seja possível compreender melhor os contornos da atividade piscatória artesanal no seio da sua própria realidade circunstancial e em referência ao contexto ecosistémico em que se inscreve.

Um olhar mais atento aos dados disponíveis sobre a atividade no arquipélago permite verificar que a pesca tem sido abordada em termos de resultados de produção (capturas e trânsitos em lota), em abordagens unilaterais (pescado/produto) com um acompanhamento científico essencialmente na área da biologia e colocando o foco na preservação ambiental, monitorizando-se e avaliando-se essencialmente a gestão de stocks das espécies capturadas e a preservação dos habitats.

No que se refere a estudos realizados em torno das questões da sustentabilidade da exploração dos recursos marinhos e impactos ambientais das atividades marítimas, onde a pesca é uma atividade abordada, destaca-se o estudo realizado por Beata (2009). Neste trabalho, a investigadora aborda a questão da sustentabilidade das pescas portuguesas, destacando a sustentabilidade da pesca de pequena escala em detrimento da pesca industrial realizada com recurso a estratégias técnicas extremamente invasivas.

Também Maria do Céu Viegas (2012), aborda a problemática da esfera de conflitos entre as Comunidades Piscatórias e a gestão dos Bio-Recursos Marinhos, avançando com importantes considerações acerca da promoção de estratégias para políticas de desenvolvimento e gestão sustentáveis das comunidades costeiras onde a pesca tem presença significativa. Viegas, Moniz \& Santos (2014), também partilham importantes inputs sobre o papel da participação dos pescadores artesanais no processo de construção de políticas públicas e cogestão da atividade piscatória, com vista à promoção de uma gestão integrada e sustentável do litoral. Estes autores destacam que é praticamente inexistente o diálogo entre estes profissionais da pesca de pequena escala, a comunidade científica, os peritos e técnicos da área e decisores políticos, alertando que esta conjuntura compromete a implementação dos planos de gestão integrada e sustentável.

Outro estudo recente é o de Natacha Carvalho (2011), o qual aborda especificamente a questão da sustentabilidade das pescas açorianas, no qual a investigadora conclui que a pesca artesanal nos Açores é mais rentável que a pesca industrial, observando que, no entanto, a maior fatia dos subsídios é aplicada na pesca industrial. A investigadora salienta ainda que a pesca artesanal (com embarcações até aos doze metros) gasta menos combustível, emprega mais gente, tem menos pesca acidental e rende mais por tonelada, sendo que nos Açores a frota de pesca é constituída na sua 
maioria por barcos até 12 metros de comprimento e apenas $10 \%$ representam embarcações com mais de 12 metros.

Olhando o estado da arte da produção académica e estudos científicos na área das ciências sociais acerca do setor das pescas em Portugal, constata-se que é muito escassa e, na sua maioria, são respeitantes a estudos de caráter etnográfico e resenhas históricas. Não obstante, alguns destes estudos, realizados recentemente, fornecem-nos dados muito importantes sobre a caraterização das comunidades piscatórias e das caraterísticas técnicas dos diferentes tipos de pesca que existem por todo o território nacional (onde o panorama reflete uma realidade múltipla extremamente complexa no que se refere à distribuição no espaço de tipos de pesca, diversidade dos tipos de artes e embarcações utilizadas). Não assumindo a pretensão de apresentar um levantamento exaustivo do estado da arte a este propósito, identificam-se, no entanto, alguns estudos cujo contributo se figura importante face à questão da pertinência da intervenção das ciências sociais na produção de conhecimento, capaz de se apresentar como recurso de apoio à decisão e gestão política com incidência no setor.

A este propósito, em 2007, no estudo publicado com o título Comunidades de pesca artesanal na costa portuguesa na última década do século XX", Souto (2007) refere que

o contributo das Ciências Sociais e Humanas para as pescas e para os pescadores tem sido negligenciado: grande parte dos problemas por nós detetados nas diversas comunidades de pescadores, muitos dos quais de grande gravidade, resultam da falta de conhecimento das realidades sociais e económicas locais e regionais (Souto, 2007, p. 14),

reforçando que "a legislação nacional de pescas revela um desconhecimento alarmante das realidades sociais, parecendo preocupar-se apenas com a defesa dos recursos vivos (isto é, com a componente biológica das pescas) e esquecendo sistematicamente a componente humana do sistema" (Souto, 2007, p. 175).

Na última década, começaram a surgir igualmente alguns estudos que nos ajudam a compreender a atividade piscatória enquanto atividade económica, dos quais se destaca, pelo seu caráter abrangente (fornecendo um retrato da realidade nacional), o trabalho anteriormente referido de Souto (2007). Neste trabalho, a par com o estudo da presença territorial das comunidades de pesca artesanal e caraterização técnica da atividade piscatória, são levantadas questões cuja reflexão se torna pertinente no âmbito de um estudo sociológico, como sejam as questões relativas à organização laboral, às incoerências legais sinalizadas pelos pescadores, ao vazio estatístico e inexistência de dados que permitam uma caraterização das comunidades piscatórias para além dos números relativos a produção e volumes totais de efetivos 
(Souto, 2007, pp. 175-176). A este propósito o investigador destaca o facto de a legislação nacional revelar um alarmante desconhecimento das realidades sociais, resultando consequentemente em legislação desadequada. Reflete ainda sobre a importância de se intervir nesta área de atividade, concluindo que as autoridades e as próprias comunidades locais têm de assumir um papel mais dinâmico e mais criativo para que se não corra o risco de rapidamente se ver desaparecer um sector tradicional que, se bem orientado, poderia ser uma contribuição para melhorar as economias locais (Souto, 2007, p. 175). Registam-se ainda os trabalhos realizados no âmbito do programa Coastwatch entre 2004 e 2008 a propósito de questões de ordenamento e território.

Considerando a incontestável importância dos contributos fornecidos por estes estudos, observa-se, não obstante, um vazio no que refere estudos que permitam avançar com retratos fidedignos da realidade do setor, como seja a caracterização demográfica e socioeconómica dos ativos da pesca, assim como dos demais atores da fileira da pesca, ou a avaliação e monitorização do impacto socioeconómico da atividade piscatória e demais atividades da fileira da pesca em termos de tecidos locais (por localidade, por ilha, por grupo de ilhas, por região...). De igual modo, deparamo-nos com igual vazio em termos de estudos que incidam, de forma multidisciplinar e ecosistémica, sobre as questões críticas que emergem ao longo dos processos de gestão do setor e de gestão dos recursos e habitats, dos quais o setor depende. E este é um vazio reconhecido pelas várias esferas de atores da fileira da pesca.

Como salienta o atual Diretor Regional das Pescas, Dr. Luís Rodrigues, "é importante fazer com que a pesca seja assumida como um setor intersectorial", 22 que tem que ser, por um lado, trabalhado por várias Secretarias (Trabalho, Formação e Qualificação Profissional, Economia, Segurança Social, Turismo...), e por outro lado, é fundamental que se aposte na produção de conhecimento sobre o setor, o qual deverá ser encarado não apenas na dimensão de atividade extrativa, mas antes com uma visão mais abrangente. Defendendo que mais do que uma atividade na qual entra em relação o pescador, a embarcação e o pescado, Luís Rodrigues aponta para a necessidade de a pesca ser encarada considerando toda a complexidade de relações que se estabelecem entre os vários atores ao nível local e regional, uma vez que desta atividade dependem muitos profissionais e muitas transações que ultrapassam a esfera da unidade de produção pescador-embarcação-pescado. Falando da fileira da pesca açoriana, na qual se inscrevem todos os atores e estruturas que dependem ou se relacionam diretamente com a atividade piscatória na região, ${ }^{23} \mathrm{o}$ Diretor Regional das Pescas salienta que "um ponto muito importante é saber produzir conhecimento! Nós sabemos muito pouco do que andamos aqui a fazer. Nós não sabemos o real impacto da nossa atividade no ecossistema" ${ }^{24}$ Reforçando esta ideia refere o fato de ser 
comum, nos congressos e encontros técnicos sobre as pescas, estarem sempre presentes vários biólogos (gente que estuda os peixes) e quase não encontrar pessoas que estudam pessoas. A este propósito acrescenta que

a sustentabilidade da pesca depende das pessoas. [...]. Existem estudos por exemplo do impacto da pesca no Goraz. Mas não tenho estudos ao contrário, ou seja, do impacto que o Goraz tem nas pessoas que o pescam. Por exemplo: se colapsar o goraz, quantas pessoas, quantas famílias são afetadas? Todo o estudo anda sempre a ser feito num só sentido, no sentido dos peixes. Nunca tenho os estudos no sentido das pessoas e é fundamental produzir conhecimento também a este nível. Aliás este conhecimento é fundamental para tomar decisões sobre a pesca, porque a pesca não é só peixe, também e principalmente são pessoas..$^{25}$

Com efeito, existe um hiato de informação disponível sobre os contornos da atividade piscatória, bem como sobre os seus atores. Não está disponível informação sistematizada e validada que permita saber quantos profissionais estão afetos à atividade em cada ilha (em mar e no apoio em terra) e quantos trabalham em atividades de relação direta com a pesca, qual o seu perfil socioeconómico, qualificação escolar e profissional, dimensão e caraterísticas do seu agregado familiar, entre outros indicadores fundamentais para que se possa falar com propriedade sobre os problemas e necessidades da atividade ao nível regional e ao nível das dimensões de ilha, assim como poder trabalhar com fundamento estratégias de promoção e desenvolvimento da pesca açoriana.

\section{Oportunidades de trabalho na esfera de investigação sociológica: contributos para uma abordagem ecossistémica a partir do estudo Representações sociais dos atores da pesca artesanal açoriana sobre as politicas públicas para a gestão sustentável dos recursos marinhos nas Ilhas Reserva da Biosfera}

Por modo a contextualizar as considerações avançadas a propósito do lugar do contributo dos atores locais e oportunidades no terreno no âmbito da investigação científica ecossistémica, importa apresentar de forma sucinta a metodologia de trabalho que tem vindo a ser aplicada ao longo da pesquisa que motivou a presente reflexão ${ }^{26}$ e a qual se partilha com o objetivo de contribuir para o processo de construção de uma metodologia de abordagem à pesca pelas ciências sociais e em processos de trabalho em cooperação interdisciplinar.

Tendo como problema de partida a existência de práticas piscatórias ilegais, referentes à infração de disposições legais que visam a preservação dos recursos 
marinhos das áreas protegidas nas ilhas açorianas classificadas como Reserva da Biosfera, o trabalho que tem vindo a ser desenvolvido nas Ilhas da Biosfera inscreve-se na esfera de conflitos entre a estratégia regional pró-sustentabilidade e as práticas locais vigentes, colocando o enfoque na ótica dos profissionais diretamente envolvidos na atividade piscatória artesanal (representações sociais dos atores locais). Parte-se, assim, da seguinte questão inicial: As políticas públicas para gestão das áreas marinhas protegidas nas Ilhas classificadas como Reserva da Biosfera são perspetivadas como pertinentes e compatíveis com atividade piscatória (pesca e apanha) pelos profissionais (atores locais)?

Com vista à compreensão da génese do problema identificado (Que motivações estão na génese da infração? Que posicionamentos manifestam os atores locais face à problemática?), a presente pesquisa, seguindo as premissas teóricas da Grounded Theory, constrói-se numa dialética constante entre reflexão crítica sustentada nas propostas teóricas tidas por referência e uma abordagem ao terreno, feita em registo de observação participante e seguindo os princípios da investigação ecossistémica.

Adotando a estratégia metodológica sistematizada no esquema proposto (figura 1), a presente pesquisa desenvolve-se ao longo de quatro momentos-chave: Recolha inicial ( $1 .^{\circ}$ Momento), cujo objetivo é sinalizar os contornos da problemática em estudo, durante o qual há lugar à análise documental, entrevistas preliminares a Stakeholders locais, aplicação de um questionário exploratório ${ }^{27}$ e dinamização de sessões de Focus Group com pescadores e apanhadores (com recurso a dinâmicas de grupo); Recolha exaustiva (2. ${ }^{\circ}$ Momento), cujo objetivo é caracterizar o efetivo de pesca: mapear a localização, frequência e tipologia das práticas ilegais; análise SWOT pesca/ políticas públicas; análise documental (colocando como estratégia chave a revisão crítica de legislação e documentos oficiais que consubstanciam as políticas públicas em causa); outras técnicas de recolha junto dos atores locais (conversas estruturadas a pescadores/apanhadores locais em contexto real de trabalho, aplicação de questionário a pescadores/apanhadores locais, sessões de Focus Group com profissionais e com atores das estruturas associativas locais e regionais da pesca; Sistematização inicial ( $3 .^{\circ}$ Momento), cujo objetivo é sistematizar os contornos da problemática, apresentar um diagnóstico sociodemográfico e económico da atividade piscatória nas ilhas em estudo, validação inicial de conteúdos a partir da partilha crítica com os atores locais (organização sistemática de dados e conteúdos recolhidos com elaboração de "dossier de análise" inicial, o qual é partilhado com os atores locais a fim de haver escrutínio e validação de conteúdos pelos participantes); Sistematização final ( $4 .^{\circ}$ Momento), cujo objetivo é a elaboração 


\section{Sistematização crítica das Políticas Públicas (leitura top-down)}

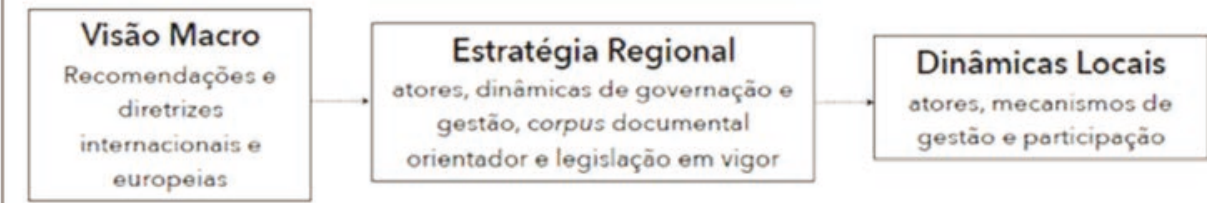

\section{Aproximação ao terreno (abordagem bottom-up)}

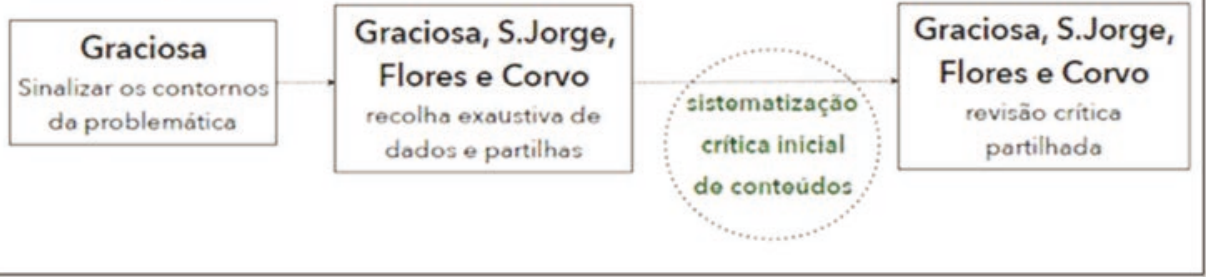

Figura 1 Estratégia metodológica para uma abordagem sociológica ecossistémica à pesca artesanal açoriana (pesca de pequena escala)

Nota: Desenho metodológico desenvolvido na Investigação Representações sociais dos atores da pesca artesanal açoriana sobre as políticas públicas para a gestão sustentável dos recursos marinhos nas Ilhas Reserva da Biosfera, por Ana Fraga, Doutoramento em Sociologia da FCSH-UNL.

do um corpus documental para análise e reflexão crítica final que possa servir de ferramenta de apoio à gestão crítica e sustentada da Pesca Artesanal Açoriana, quer pelos atores locais e estruturas associativas, quer pela esfera da decisão política nos processos de avaliação e implementação das políticas públicas.

A par do reconhecimento, por parte dos atores políticos e atores locais, da necessidade de realização de um diagnóstico pluridisciplinar sobre a realidade efetiva da atividade piscatória na região e levantamento de oportunidades e desafios que se colocam à fileira da pesca açoriana, numa primeira abordagem ao terreno identificam-se algumas necessidades de trabalho, onde a pesquisa sociológica se figura como fundamental. ${ }^{28}$

Entrevista a pescador, comunicação pessoal, sessão focus group 13/04/2017:29

Estamos de uma maneira que sabemos que nos temos que organizar e eu acredito mesmo que a pesca só é sustentável em autogestão por ilha e se formos nós próprios a fiscalizarmo-nos. Estudos como o que a senhora está a fazer são muito importantes para nós porque ninguém liga à pesca. Só sabem ver os totais em lota, mas a verdade verdadinha é que ninguém sabe nada da pesca. Nem os políticos que fazem as leis. Ninguém sabe quantos somos, o que se ganha da pesca ou como nos organizamos... nós que vamos ao 
mar e que cá andamos sabemos quem é quem e quem é que realmente vive da pesca... ainda bem que as pessoas da universidade começam a perceber isso...

Primeiramente é crucial proceder a um diagnóstico demográfico e socioeconómico sobre os ativos da fileira da pesca, com foco prioritário nos ativos da pesca (pescadores, apanhadores, armadores, estrutura social de apoio em terra). No entanto, este é um trabalho que urge ser encarado de forma ecossistémica e chamando ao processo os vários atores intervenientes, uma vez que a par da dificuldade de acesso aos dados ${ }^{30}$ que permitam sistematizar a informação necessária e identificar dados em falta para proceder a este diagnóstico, os dados estatísticos disponíveis sobre os atores da pesca não permitem uma leitura fidedigna da realidade (número de profissionais, qualificação e certificação, situação de trabalho). Com efeito, os dados disponíveis de forma sistematizada sobre a atividade piscatória incidem sobre volumes totais de produção (volumes de pescado descarregado em lota, valores totais de venda em lota/ $1 .^{a}$ venda).

Outra questão que urge trabalhar com vista à promoção de estratégias de intervenção local sustentada para a promoção da pesca artesanal açoriana é a recolha de dados sobre a estrutura organizacional e dinâmica da atividade piscatória (organização laboral, estrutura de negócio, modelos de diagnóstico de viabilidade económica, impactos sociais da atividade nos tecidos locais).

A par com esta necessidade de produzir conhecimento sobre as pescas nos Açores, uma necessidade identificada no terreno, destacada pelos próprios pescadores e demais atores locais, é a de se proceder a uma revisão crítica e sistemática do corpus legal que enquadra a atividade piscatória na região. Segundo os profissionais da pesca açoriana, esta necessidade prende-se com o fato de grande parte das medidas legais, que alegadamente visam a preservação dos recursos e habitats e que impõem restrições à atividade piscatória, não terem fundamentação científica nem estarem alicerçadas em qualquer conhecimento técnico validado sobre os benefícios reais da restrição ou impactos resultantes do seu não cumprimento. Este é, aliás, um problema identificado por algumas Associações de Pescadores, as quais têm procurado chamar atenção sobre a urgência de promover estudos de incidência local e que contemplem as especificidades de cada ilha, sem menosprezar o conhecimento local dos profissionais da pesca, os quais se reconhecem como parceiros capazes de contribuir neste processo.

Entrevista a pescador, comunicação pessoal, sessão focus group 13/04/2017:31

Temos um grande problema! Existem muitas restrições. (...) atualmente existem muitas restrições...não nos deixam trabalhar... (...) e os senhores que se sentam a fazer portarias atrás de portarias não conhecem a realidade da nossa ilha (...) não temos leis adequadas às Pescas. Somos os primeiros a querer preservar o nosso mar e 
defendemos que é preciso proteger porque a pesca da nossa ilha tem futuro, e muito! (...) mas a lei que há não serve a pesca (...) e quem anda ilegal pode ter a certeza que é por necessidade, porque é preciso pôr a comida na mesa e além disso estamos a pescar como sempre fizemos, agora é que criaram restrições e mais restrições que ninguém entende.

A este propósito importa salientar que, ao longo do trabalho que tem vindo a ser realizado no terreno, ${ }^{32}$ no qual se dá especial destaque ao levantamento de posturas e posicionamentos dos atores locais, tem-se mostrado fundamental a valorização dos olhares de "dentro" aos problemas e conflitos locais, assim como às falhas no processo de participação. Dirigentes associativos das associações de pescadores e a maioria dos pescadores, mestres e armadores têm-se revelado muito colaborantes e participativos na identificação e discussão de problemas, contribuindo de forma assertiva com o seu conhecimento local especializado. Observa-se, aliás, nestes atores locais um autorreconhecimento de capacidade de análise crítica dos conflitos locais e da sua capacidade para colaboração ativa na procura de soluções, o que os coloca na posição de stakeholder-chave.

\section{Considerações finais}

Encarando a pesca artesanal açoriana enquanto sistema socioecológico, que deve ser abordado de forma sistémica e transdisciplinar, nomeadamente enquanto objeto de estudo das ciências sociais, identifica-se a necessidade premente de uma estratégia concertada de produção de conhecimento que permita aferir os contornos efetivos da realidade circunstancial em que esta atividade se desenvolve.

Em concordância com as orientações da FAO $(1999 ; 2003$; 2008) para a gestão da pequena pesca, numa perspetiva de adoção de um modelo de gestão partilhada da pesca entre as diferentes esferas de atores (poder político - profissionais), considera-se a investigação sociológica como elemento-chave em estratégias de desenvolvimento local sustentável de comunidades costeiras. O investimento na produção de conhecimento sobre os atores da pesca e sobre as dinâmicas locais da atividade piscatória configura-se como necessidade identificada pelos próprios atores locais e constitui em si um espaço de oportunidades de trabalho no âmbito da investigação sociológica, assim como abre novas oportunidades de trabalho aos sociólogos, na qualidade de técnicos especializados com capacidade de contributo na monitorização dos planos de intervenção local e apoio a estratégias concertadas e sustentadas de desenvolvimento local das comunidades costeiras. 
Se, numa primeira fase, o papel do sociólogo e demais especialistas das ciências sociais assume particular importância neste necessário e urgente processo de diagnóstico da pesca artesanal açoriana, a montante, a sua presença enquanto facilitador em processos de gestão participada (elo de comunicação e interação entre os diferentes atores e diferentes fontes de conhecimento) figura-se como pertinente e como uma mais-valia reconhecida, quer localmente pelos profissionais da pesca, que pelos atores de decisão e gestão política.

Com efeito, urge a aposta na promoção da pesquisa e reflexão crítica sobre as questões sociais inerentes ao setor da pesca (nas quais, numa abordagem ecosistémica, se incluem as questões relativas à gestão dos recursos marinhos e habitats costeiros), com vista à consolidação de um corpo crítico que possa efetivamente avançar com "contributos para uma reflexão sustentada" (sustentada porque devidamente enquadrada no contexto da realidade circunstancial e da problemática destacada, assim como sustentada porque "fora" do registo do discurso de opinião atualmente vigente na comunicação social sobre a gestão das pescas e dos recursos e habitats, raramente alicerçado em contributos científicos e/ou assente em visões unilaterais/parcelares). Este é, neste sentido, contributo fundamental para os processos e estratégias concertadas de desenvolvimento local sustentável das comunidades costeiras.

\section{Notas}

1 In Decreto Legislativo Regional n. ${ }^{\circ} 15 / 2012$ / A, 2 de abril de 2012, que estabelece o Regime jurídico da conservação da natureza e da proteção da biodiversidade da Região Autónoma dos Açores.

2 Conf. Art. ${ }^{\circ}$ 51, Decreto Legislativo Regional n. ${ }^{\circ}$ 15/2012/A, 2 de abril de 2012.

3 O termo prática contra-ordenacional é usado para designar as ações praticadas (fatos) que constituem infração punível com coima. O termo contraordenação conforme definido no Decreto-Lei n. ${ }^{\circ 244 / 95}$, de 14 de novembro, que altera e republica o Regime Geral de Contraordenações ("constitui contraordenação todo o facto ilícito e censurável que preencha um tipo legal no qual se comine uma coima"). O termo infração define a transgressão/violação de preceito ou regra/disposição legal.

"Faina" é a expressão utilizada entre pescadores para designar o trabalho realizado a bordo de embarcações de pesca. Encontrando a sue etimologia no catalão antigo, a expressão compreende as referências ao serviço realizado, ao ofício e artes típicas da pesca artesanal. É também definida como "lida" de pesca pelas comunidades piscatórias em Portugal.

5 Trabalho de investigação desenvolvido por Ana Fraga, com vista à obtenção do Grau de Doutor em Sociologia, pela Faculdade de Ciências Sociais e Humanas da Universidade Nova de Lisboa. 
Ao longo da presente proposta, os termos, "utilização sustentável", "biodiversidade", "conservação", "preservação", "recursos", "habitats" são assumidos conforme definidos e delimitados pela Assembleia Legislativa da Região Autónoma dos Açores no Decreto Legislativo Regional n. ${ }^{\circ}$ 15/2012/ A, 2 de abril de 2012, que estabelece o Regime jurídico da conservação da natureza e da proteção da biodiversidade da Região Autónoma dos Açores. A saber: Art. . 3. $^{\circ}, 1$ ) “Biodiversidade" ou "diversidade biológica", a variabilidade entre os organismos vivos de todas as origens, incluindo, inter alia, os ecossistemas terrestres, marinhos e outros ecossistemas aquáticos e os complexos ecológicos dos quais fazem parte; compreende a diversidade dentro de cada espécie, entre as espécies e dos ecossistemas; o) "Conservação", o conjunto das medidas e ações necessárias para manter ou restabelecer os habitats naturais e as populações de espécies da flora e da fauna selvagens num estado favorável; p) "Conservação da natureza", a gestão da utilização humana da natureza, de modo a compatibilizar de forma perene o seu uso e a capacidade de regeneração de todos os recursos vivos; dd) "Ecossistema", um complexo dinâmico de comunidades vegetais, animais e de microrganismos e o seu ambiente não vivo, interagindo como uma unidade funcional; zz) "Habitats naturais", as áreas terrestres ou aquáticas, naturais ou seminaturais, que se distinguem por caraterísticas geográficas abióticas e bióticas; nnn) "Recursos biológicos”, os recursos genéticos, organismos ou partes deles, populações ou qualquer outro tipo de componente biótico dos ecossistemas de valor ou utilidade atual ou potencial para a humanidade; zzz) “Utilização sustentável”, a utilização dos componentes da biodiversidade de um modo e a um ritmo que não conduza a uma diminuição a longo prazo da diversidade biológica, mantendo assim o seu potencial para satisfazer as necessidades e as aspirações das gerações atuais e futuras. Note-se que, não obstante não ser alvo desta reflexão discutir o alcance e uso dos termos "conservação" e "preservação", observa-se que ambos os termos serão utilizados com conformidade com o seu uso nos documentos oficiais de suporte à publicação das ferramentas de gestão estratégica do Governo Regional para a implementação das políticas públicas para a Rede de Áreas Protegidas dos Açores, nomeadamente no que concerne a gestão das Reservas da Biosfera, as quais visam estabelecer mecanismos de conservação, preservação e de gestão dos ecossistemas, da biodiversidade e dos valores e recursos naturais, paisagísticos, científicos e espirituais dos Açores, considerando de igual modo o uso destes termos no contexto dos documentos oficiais de apoio à gestão do Parque Marinho dos Açores, que visam assegurar a manutenção e preservação da biodiversidade marinha e a adoção de medidas de proteção, valorização e uso sustentado dos recursos marinhos, através da integração harmoniosa das atividades humanas e estudos científicos (conf. Art. ${ }^{\circ} 5^{\circ}$ e 30. ${ }^{\circ}$, DLR n. ${ }^{0} 15 / 2012 / A, 2$ de abril).

7 O uso da terminologia desenvolvimento local sustentado remete para a proposta apresentada por Jara (1998), por referência ao conceito de desenvolvimento sustentável de Sachs $(2007 ; 2008)$, o qual assenta na premissa de que a sustentabilidade do desenvolvimento local implica um processo participado e articulado de construção de caminhos, através de metodologias de microplaneamento 
participativo, envolvendo todos os atores intervenientes, numa dialética de pequena escala, onde se posicionam, de forma coerente e informada, estratégias globais à escala local (em articulação de contributos científicos e conhecimento local), dinamizado no sentido de organizar um processo de aprendizagem social, como instrumento dinâmico para orientar coletivamente os processos de mudança local - requisito básico para viabilizar processos de desenvolvimento sustentável (conf. Jara (1998, pp. 112-113)).

8 No mar dos Açores, a pesca, sem ou com auxílio de embarcações regionais, só pode ser exercida por meio dos seguintes métodos de pesca: a) Apanha; b) Pesca à linha; c) Pesca por armadilha; d) Pesca por arte de levantar; e) Pesca por arte de cerco; f) Pesca por rede de emalhar. Em termos de caraterísticas de frota, esta enquadra-se no perfil de pesca artesanal apresentado anteriormente, pois esta é constituída maioritariamente por embarcações de pesca local e de embarcações de pesca costeira, sendo o número de embarcações de pesca do largo muito reduzido.

9 Diploma base que regulamenta a atividade de pesca profissional na Região Autónoma dos Açores: Decreto Legislativo Regional n. ${ }^{2} 29 / 2010 /$ A, 9 de novembro, alterado e republicado em Anexo ao Decreto Legislativo Regional n. ${ }^{031 / 2012 / A, ~ d e ~} 6$ de julho (Quadro Legal da Pesca Açoriana).

10 Aprovada em Conselho de Ministros no dia 16 de Novembro de 2006, dia Nacional do Mar, RCM n. ${ }^{\circ} 163$, de 12 de Dezembro de 2006. Documento oficial de consulta pública, publicado em Março de 2007, pelo Ministério da Defesa Nacional - Estrutura de Missão para os Assuntos do Mar.

11 Pescador matriculado: profissional que exerce a atividade da pesca e se encontra inscrito numa Capitania ou Delegação Marítima (conf. INE (2015)).

12 Esta classificação é feita por referência à área onde podem operar: I) Embarcações regionais de pesca local- a) Quando de convés aberto - dentro da zona até às 6 milhas da costa da ilha onde estão registadas; b) Quando de convés aberto, parcialmente fechado à proa, com cabina - dentro da zona até às 12 milhas da costa da ilha onde estão registadas; c) Quando de convés fechado - dentro da zona até às 30 milhas da costa da ilha onde estão registadas; II) Embarcações regionais de pesca costeira- a) $\mathrm{Na}$ área circunscrita pelo limite exterior do Mar dos Açores; b) Na área circunscrita pelo limite exterior da Subárea da Madeira da Zona Económica Exclusiva nacional; c) Na área entre o Mar dos Açores e a Subárea da Madeira da Zona Económica Exclusiva nacional; d) Nos bancos a sul do Mar dos Açores até à latitude de $30^{\circ} \mathrm{N}$; e) Nos bancos a norte do Mar dos Açores até à latitude de $45^{\circ} \mathrm{N}$.; f) Nos bancos Josephine e Ampere; III) Embarcações regionais de pesca do largo- As que podem operar em qualquer área, com exceção do Mar dos Açores.

13 Conf. GaCS/HB, comunicação on-line em http://azores.gov.pt/Portal/pt/entidades/vp/noticias , 10 de Maio de 201).

14 Prevendo-se a criação do Fundo Regional de Apoio à Coesão Económica.

15 A ilha do Corvo e a ilha Graciosa em 2007, a ilha das Flores em 2009 e as Fajãs de São Jorge em 2016 passaram a fazer parte da Rede Mundial de Reservas da Biosfera da 
UNESCO, classificação atribuída pelo Bureau do Conselho Internacional de Coordenação do Programa MAB (O Homem e a Biosfera).

16 O Decreto Legislativo Regional n. ${ }^{0}$ 15/2007/A, de 25 de Junho, consagrou o regime jurídico de classificação e gestão da Rede Regional de Áreas Protegidas da Região Autónoma dos Açores.

17 Rede europeia de áreas protegidas para conservação dos habitats e espécies selvagens raras, ameaçadas ou vulneráveis na União Europeia, criada pela Diretiva 92/43/CEE, de 21 de Maio de 1992, com a finalidade de alcançar os objetivos definidos pela Convenção sobre a Diversidade Biológica, aprovada na Cimeira da Terra no Rio de Janeiro, em 1992.

18 Os seguintes decretos legislativos regionais configuram a criação dos Parques Naturais de Ilha das ilhas classificadas como Reserva da Biosfera: Decreto Legislativo Regional n. ${ }^{\circ} 45 / 2008 / A$ (Parque Natural da Ilha Graciosa), Decreto Legislativo Regional n. ${ }^{\circ} 8 / 2011 /$ A (Parque Natural da Ilha das Flores) e Decreto Legislativo Regional n. ${ }^{\circ} 44 / 2008 /$ A (Parque Natural da Ilha do Corvo.)

19 Ao longo do trabalho de campo em que se alicerça o presente ensaio, esta surge com uma questão crítica central: O estudo de caso em curso nas Ilhas da Biosfera aborda a questão do desafio de gestão dos comuns (recursos pesqueiros e habitats) e coloca-se na esfera de conflitos entre estratégia regional açoriana pró-sustentabilidade e as práticas piscatórias que manifestam resistência e/ou desrespeito pelas disposições legais que visam a preservação dos recursos (práticas piscatórias ilegais/desviantes). Através da compreensão das representações sociais dos atores locais, procura-se contribuir para o debate crítico da problemática sociológica das motivações para o desvio e para a compreensão do fenómeno de resistência a determinadas medidas das políticas públicas, algo que se assume como fundamental para a análise e revisão crítica das mesmas.

20 Note-se que, não obstante haver legislação que se aplica a todo território nacional, existe um corpus legal específico para o arquipélago dos Açores, nomeadamente no que respeita o quadro legal da pesca açoriana, assim como outras disposições legais que se prendem com questões ambientais e de preservação dos recursos.

21 Dados do estudo exploratório da investigação As representações sociais dos atores da pesca artesanal açoriana sobre as políticas públicas para a gestão sustentável dos recursos marinhos das Ilhas Reserva da Biosfera (Graciosa, S. Jorge, Flores e Corvo), desenvolvida no âmbito da tese de Doutoramento em Sociologia pela FCSH-UNL, por Ana Fraga.

22 In Notas de campo: Registo de observação participante (Sessão aberta promovida pela Associação de Pescadores Graciosenses, com participação do Diretor Regional das Pescas, Graciosa 03.05.2017), Dossier de Projeto de Investigação Representações sociais dos atores da pesca artesanal açoriana sobre as politicas públicas para a gestão sustentável dos recursos marinhos nas Ilhas Reserva da Biosfera, de Ana Fraga, Doutoramento em sociologia da FCSH-UNL.

23 Pescadores, Armadores, Comerciantes de Pescado, Cooperativas, Empresas de Transformação de Pescado, Associações de Pescadores, Lotaçor e seus funcionários, Inspeção Regional das Pescas, Direção Regional das Pescas, Polícia Marítima, Marinha Portuguesa, Guarda Nacional Republicana, cientistas, etc. 
24 In Notas de campo: Registo de observação participante (Sessão aberta promovida pela Associação de Pescadores Graciosenses, com participação do Diretor Regional das Pescas, Graciosa 03.05.2017), Dossier de Projeto de Investigação Representações sociais dos atores da pesca artesanal açoriana sobre as politicas públicas para a gestão sustentável dos recursos marinhos nas Ilhas Reserva da Biosfera, de Ana Fraga, Doutoramento em sociologia da FCSH-UNL.

25 in Notas de campo: Registo de observação participante (Sessão aberta promovida pela Associação de Pescadores Graciosenses, com participação do Diretor Regional das Pescas, Graciosa 03.05.2017), Dossier de Projeto de Investigação Representações sociais dos atores da pesca artesanal açoriana sobre as políticas públicas para a gestão sustentável dos recursos marinhos nas Ilhas Reserva da Biosfera, de Ana Fraga, Doutoramento em sociologia da FCSH-UNL.

26 Projeto de Investigação Representações sociais dos atores da pesca artesanal açoriana sobre as políticas públicas para a gestão sustentável dos recursos marinhos nas Ilhas Reserva da Biosfera, de Ana Fraga, Doutoramento em sociologia da FCSH-UNL.

27 No estudo em referência este foi aplicado a 20 atores locais na ilha Graciosa, ilha da Biosfera assumida como ilha de referência para a definição de estratégias de recolha (conf. Fraga (2016)).

28 Diagnóstico inicial de necessidades e oportunidades identificadas no terreno no âmbito do Projeto de Investigação Representações sociais dos atores da pesca artesanal açoriana sobre as políticas públicas para a gestão sustentável dos recursos marinhos nas Ilhas Reserva da Biosfera, de Ana Fraga, Doutoramento em sociologia da FCSH-UNL.

29 conf. Nota de rodapé 17.

30 Os dados disponíveis e com informação pertinente estão dispersos por diversos documentos oficiais de diversas entidades (Autoridade Marítima, Direção das Pescas, Lotaçor, Inspeção Regional das Pescas).

31 conf. Nota de rodapé 45.

32 conf. Nota de rodapé 45.

As autoras escrevem segundo o AO ratificado em 2008 (Acordo Ortográfico da Língua Portuguesa, de 1990 - em vigor desde 2009).

\section{Referências}

Associação Fórum Empresarial da Economia do Mar - AFEM. (2009). O hypercluster da economia do mar em Portugal. Um novo domínio estratégico e um fator de afirmação (Relatório final). Lisboa: SaeR/ACL.

Beata, A. F. R. (2009). Environmental impact and sustainability of Portuguese fisheries (Tese de doutoramento). Universidade de Lisboa, Faculdade de Ciências, Departamento de Biologia Animal, Lisboa.

Bruckmeier, K. (2016). Social-ecological transformation. Basingstoke, Reino Unido: Palgrave Macmillan. 
Carvalho, N. (2011). Sea to shore: An economic evaluation of the Azorean comercial fisheries (Tese de doutoramento). Universidade dos Açores, Horta.

Decreto Legislativo Regional n. ${ }^{\circ}$ 15/2012/ A (2012). Estabelece o regime jurídico da conservação da natureza e da proteção da biodiversidade. Diário da República, 1. ${ }^{a}$ série. N. ${ }^{\circ} 66$ (02/04/2012), 1625-1713.

Direção Regional dos Assuntos do Mar. (S.d). Plano mar - Portugal - Açores (2015-2020). Plano de ação trazendo coerência e integração à gestão do mar nos Açores. Região Autónoma dos Açores: Secretaria Regional do Mar, Ciência e Tecnologia. Retrieved from http://www.azores.gov.pt/Gra/SRMCT-MAR/ conteudos/livres/Plano_Mar-Portugal_Acores.htm

Dubet, F. (1994). Sociologie de l'expérience. Paris: Seuil.

FAO. (1999). Indicators for sustainable development of marine capture fisheries. FAO technical guidelines for responsible fisheries, No. 8. Rome: Food and agricultural organization of the United Nations.

FAO. (2003). Fisheries management 2. FAO technical guidelines for responsible fisheries, No. 4. Rome: Food and agricultural organization of the United Nations.

FAO. (2008). Towards integrated assessment and advice in small-scale fisheries: Principles and processes. FAO fisheries and aquaculture technical paper, No. 515. Rome: Food and agricultural organization of the United Nations.

FAO. (2009). Fisheries management 4. FAO technical guidelines for responsible fisheries- The ecosystem approach to fisheries, No. 4. Rome: Food and Agricultural Organization of the United Nations

Faugeron, C., et al. (1976). De la deviance et du controle social (Représentations et attitudes). Paris: Presses de COPEDITH.

Fraga, A. (2016). A pesca açoriana nas ilhas da biosfera: Modus operandi e desafios às políticas públicas para a gestão dos recursos e áreas marinhas protegidas. A problemática da infração. Comunicação apresentada em Jornadas do Mar 2016. Novos Rumos, Novos Desafios, Almada.

Fraga, A. (2017). Artisanal fishery in the Azorean islands part of UNESCO's Biosphere Reserves: Regional strategy, legal framework and local "threatening" practices in the eyes of local fishermen. Comunicação apresentada em MARE Conference. People and the Sea IX: Dealing with Maritime Mobilities, Amsterdão.

INE. (2011). Estatísticas da Pesca 2015, I.P. Lisboa. Retrieved from https://www.ine.pt/xportal/xmain?xpgid=ine_main\&xpid=INE

INE. (2015). Estatísticas da Pesca 2015, I.P. Lisboa. Retrieved from https://www.ine.pt/xportal/xmain?xpgid=ine_main\&xpid=INE

INE. (2016). Estatísticas da Pesca 2015, I.P. Lisboa. Retrieved from https://www.ine.pt/xportal/xmain?xpgid=ine_main\&xpid=INE

Jara, C. J. (1998). A sustentabilidade do desenvolvimento local: Um processo em construção. Brasília/Recife: Instituto Interamericano de Cooperação para Agricultura/Secretaria de Planejamento do Estado de Pernambuco - SEPLAN. Jodelet, D. (Org.) (1989). As representações sociais. Rio de Janeiro: Ed. UERJ. 
Lacerda, R. P. (2008, 10, 20). Pescas: Que futuro?, Voz dos Marítimos. Retrieved from http:/ / www.pescas.net/viewOP.php?id=3576

Lima, R. C. P. (2001). Sociologia do desvio e interacionismo. Tempo Social. Revista de Sociologia da USP, 13(1), 185-201.

Merton, R. K. (1964). Anomie, anomia and social interaction: Contexts of deviant behavior. In M. B. Clinard (Org.), Anomie and deviant behavior: A discussion and critique (pp. 213-242). New York: The Free Press of Glencoe.

Ministério da Agricultura do Desenvolvimento Rural e das Pescas. Direcção-Geral das Pescas e Aquicultura (MADRP-DGPA). (2007). Plano estratégico nacional para a pesca 2007. Retrieved from http://www.promar.gov.pt/Download/PROMAR/PEN_Pesca.pdf Ministério da Defesa Nacional. Estrutura de Missão para os Assuntos do Mar. (2007). Estratégia nacional para o mar. Retrieved from http://www.mdn.gov.pt

Moniz, A. B., Godinho, M. M., \& Kovács, I. (Orgs.) (2000). Pescas e pescadores: Futuros para o emprego e recursos. Oeiras: Celta.

Ostrom, E. (1990). Governing the commons: The evolution of institutions for collective action. Cambridge: Cambridge University Press.

Ostrom, E. (1997). A behavioral approach to the rational choice theory of collective action: Presidential address. American Political Science Association, 92(1), 1-22.

Ostrom, E. (2008). The challenge of common-pool resources. Environment: Science and Policy for Sustainable Development, 50(4), 8-21. Retrieved from http://www.environmentmagazine.org

Ostrom, E. (2010). A general framework for analyzing sustainability of social-ecological systems. Science, 325, 419-422.

Ostrom, E., Gardner, R., \& Walker, J. (1994). Rules, games, and common-pool resources. Ann Arbor: James Editors, University of Michigan Press.

Ostrom, E., \& Hess, C. (2006). Understanding knowledge as a commons: From theory to practice. Cambridge, Massachusetts: The MIT Press.

Ostrom, E., Wynne, S., \& Schroeder, L. (1993). Institutional incentives and sustainable development: Infrastructure policies in perspective. Oxford: Westview Press.

Rodrigues, L., et al. (2008). Artes de pesca dos Açores: Tecnologia de pesca e marinharia. Rabo de Peixe: Associação Marítima Açoriana.

Sachs, I. (2007). Rumo a' ecossocioeconomia: Teoria e prática do desenvolvimento. São Paulo: Cortez.

Sachs, I. (2008). Caminhos para o desenvolvimento sustentável. Rio de Janeiro: Garamond.

Secchi, L. (2010). Políticas públicas: Conceitos, esquemas de análise, casos práticos. São Paulo: Cengage Learning.

Souto, H. (2003, Março). Comunidades de pesca artesanal em Portugal. Comunicação apresentada à Academia de Marinha, Lisboa.

Souto, H. (2007). Comunidades de pesca artesanal na costa portuguesa na última década do século XX. Lisboa: Academia da Marinha.

Viegas, M. C. (2012). Comunidades piscatórias e bio-recursos marinhos: Estratégias para políticas de desenvolvimento e gestão sustentáveis (Tese de doutoramento). Universidade Nova de Lisboa, Faculdade de Ciências e Tecnologias, Lisboa. 
Viegas, M. C., Moniz, A. B., \& Santos, P. T. (2014). Artisanal fishermen contribution for the integrated and sustainable coastal management: Application of strategic SWOT analysis. Procedia- Social and Behavioral Sciences, 120, 257-267.

Ana Fraga. Investigadora do CICS.NOVA - Aluna do Doutoramento de Sociologia da Faculdade de Ciências Sociais e Humanas da Universidade Nova de Lisboa e Investigadora da Autoridade Marítima Nacional. Licenciatura em Filosofia pela Faculdade de Letras da Universidade do Porto, Pós-Graduação em Ciências da Comunicação - Comunicação, Educação e Cidadania pela Universidade do Minho. Experiência profissional na área de formação no sctor das pescas entre 2005 e 2008 (Formadora da Mútua dos Pescadores e da Forpescas nas áreas de Cidadania e Empregabilidade, Desenvolvimento Pessoal e Social, Dinâmica de Projeto e Dinâmica Associativa e Cooperativa). Experiência profissional na área da fiscalização da atividade piscatória desde 2008, na qualidade de Polícia Marítima, atualmente a prestar serviço na Ilha Graciosa, Açores.

Lucinda Jordão. Assistente Social - Técnica Superior do Município da Figueira da Foz desde 1980, Especialista em Intervenção Comunitária. Licenciatura em Serviço Social pelo Instituto Superior de Serviço Social de Coimbra. Experiência profissional na direção dos Serviços Municipais de Habitação, da Divisão de Assuntos Sociais e Educação e do Departamento de Assuntos Sociais. Experiência profissional em funções na Rede Social - Conselho Local de Ação Social. Conselheira Local para a Igualdade. Assistente Convidada da Área de Poder Local da Licenciatura em Serviço Social, Instituto Superior Bissaya-Barreto - Coimbra. Orientadora de Estágio, no Município da Figueira da Foz, de alunos da Licenciatura em Serviço Social - Instituto Superior Miguel Torga e Mestrado em Sociologia - Faculdade de Economia da Universidade de Coimbra. Supervisora de Estágios do $5^{\circ}$ Ano da Licenciatura em Serviço Social - Setor de Segurança Social, Instituto Superior Miguel Torga Coimbra. Formadora no Módulo Ação Social e Turismo do $1 .{ }^{\circ}$ Curso Complementar de Desenvolvimento Local - Centro de Estudos e Formação Autárquica.

Data de submissão: 16/06/2017 | Data de aceitação: 15/09/2017 